\title{
Coleta de tecido lamelar equino
}

João Pedro Hübbe Pfeifer, Vitor Hugo Santos, Gustavo dos Santos Rosa, Betsabéia Heloísa Gentilha Milani, Jaqueline Brandão de Souza, Andre Massahiro Teramoto Krieck, Jose Celio de Figueiredo Rolandi, Ana Liz Garcia Alves

Faculdade de Medicina Veterinária e Zootecnia, Universidade Estadual Paulista (UNESP), Botucatu, SP, Brasil

*Autor correspondente

e-mail: pfeifer@fmvz.unesp.br

\section{Resumo}

A laminite é uma enfermidade com alta incidência nos equinos. Atualmente, os estudos que a investigam em sua grande maioria realizam coleta do tecido lamelar do casco para avaliar os efeitos causados pela laminite na região de adesão entre as lâminas epidérmicas e dérmicas. A coleta de tecido lamelar do casco equino é realizada de acordo com as diferentes técnicas já descritas na literatura. O objetivo desse trabalho é descrever uma alternativa rápida para coleta de biópsia do casco equino. Foi realizada a coleta no casco de 4 animais cuja causa mortis não tenha relação com alterações da região do casco. Os membros foram desarticulados na região metacarpo-falângica e higienizados com água sanitária. Após antissepsia cirúrgica, estes foram envoltos por um campo estéril, deixando acesso apenas na região dorsal da parede do casco. As regiões coletadas de cada casco foram padronizadas em terço médio-proximal na face dorsal (D), dorso lateral (DL) e dorso medial (DM), todas aproximadamente $2 \mathrm{~cm}$ distal à banda coronária. A retirada dos fragmentos foi realizada utilizando uma serra-copo de 1,5 cm de diâmetro, acoplada a uma furadeira (ambas estéreis). A perfuração foi irrigada com solução fisiológica de $\mathrm{NaCl}$ 0,9\%, para evitar o aquecimento da amostra e consequente perda da qualidade tecidual. A profundidade foi atingida de acordo com a percepção da serra ao tocar a transição entre tecido córneo e derme, em torno de $2 \mathrm{~cm}$. Subsequentemente, com a própria serra-copo, os fragmentos epidérmicos foram luxados da derme com movimentos em direção proximal e distal, e então extraídos. Foi possível notar melhor análise in vitro dos fragmentos oriundos da região dorsal do casco, provavelmente pela menor angulação em que a serra-copo é posicionada, em vista da maior angulação das regiões lateral e medial. Este método mostrou-se eficaz quando utilizado para pesquisas que necessitam da rápida coleta após o óbito do animal, com subsequentes análises in vitro.

Palavras-chave: Biópsia. Equinos. Estojo córneo. 